\title{
Personality And Behavioural Factors Associated With Test- Anxiety Among Schools Students In Kolkata.
}

\author{
Dr. Sadhan Das Gupta ${ }^{1}$, Sreeparna Dutta ${ }^{2}$ \\ ${ }^{I}$ (Professor and Head, Dept. Of Applied Psychology, Univ of Calcutta, India \\ ${ }_{2}^{2}$ (Research Associate, ICSSR, Dept. Of Applied Psychology, Univ of Calcutta.India
}

\begin{abstract}
Test-anxiety is actually a type of performance anxiety- a feeling someone might have in a situation where performance really counts or when the pressure is on to do well. Test-anxiety is defined as the "set of phenomenological, physiological, and behavioral responses that accompany concern about possible negative consequences or failure on an exam or similar evaluative situation" (Zeidner, 1998). The present paper examined whether personality and behavioural factors were associated with test anxiety among school students. Reactive-Proactive Aggression Questionnaire, Test anxiety inventory, Self-Report Emotional Intelligence Scale and Junior Eyesenk Personality Questionnaire was used to assess reactive and proactive aggression, test anxiety, emotional intelligence and personality dimensions. The sample consisted of 143 school students of class 11 and 12 both males and females from different higher secondary schools in Kolkata. Students from all streams (science, humanities and commerce) were considered for the study. Results showed that reactive aggression, neuroticism and psychoticism were significantly positively correlated with test anxiety whereas emotional intelligence was significantly negatively correlated with it. Regression analysis revealed reactive aggression, emotional intelligence and neuroticism as possible predictors of test anxiety.
\end{abstract}

Keywords - Aggression, Emotional intelligence, Personality, Test anxiety.

\section{Introduction}

Test anxiety is a sort of anxiety which appears in a specific situation that has symptoms like general anxiety, such as sweating, heart beat increase, uneasiness, worry, doubt, hand trembling, dizziness, and the like. Sarason and Mandler (1952) had started seriously to research about test anxiety [1]. Sarason defines test anxiety as a type of "self-preoccupation" which is determined by understatement and feeling doubt about one's own capabilities. Although some anxiety before test taking is normal, and even necessary to do well, test anxious student's experience crippling anxiety that can limit their ability to perform to their real level of proficiency [2]. So test-anxiety is actually, a type of performance anxiety- a feeling someone might have in a situation where performance really counts or when the pressure is on to do well. It is a psychological condition where a person experiences distress before, during, or after a test or other assessment to such an extent that this anxiety causes poor performance or interfe-res with normal learning. Test-anxiety is defined as the "set of phenomenological, physiological, and behavioral responses that accompany concern about possible negative consequences or failure on an exam or similar evaluative situation" [3]. Although TA is known to depend on situational variables, such as levels of motivation, task complexity, and the practical consequences of high or low performance [4], it varies markedly from one individual to another. Thus, some individuals will be relatively calm when it comes to completing a test, whilst others will generally "perceive examinations as more dangerous or threatening and experience more intense levels of state anxiety when taking tests" [5]. In this paper an attempt has been made to find out the factors associated with test-anxiety and the predictors of test-anxiety.

Previous works done on test-anxiety has mainly focussed on a broader field of performance anxiety and its variables. Studies have also found that performance anxiety is facilitated by perfectionism and personal control [6]. There are several studies that have shown that strong association exists between test-anxiety and test performance, this indicates that test-anxiety influences the performance and has damaging effects. This has initiated research to find the factors that are associated with TA.

Though only a little work has been done in this context we have tried to draw in relation from other anxiety related studies. Recently there have been several studies linking aggression with anxiety. Research also suggested that anxiety may play a role in the manifestation of reactive aggression. Compared to proactive aggressive children, reactive aggressive children are more likely to have a history of abuse and anxiety disorder symptoms [7-8]. Also recent studies has paid attention to the effect of emotional intelligence on academic success in education [9]. Emotional intelligence, which reveals synthesis between cognitive and affective processes, has stimulated some research, mostly in the fields other than second language acquisition/learning. For instance, Stottlemayer (2002) in a study of EQ and its relation to student achievement among 200 eleventh and twelfth grade American students in Texas found that EI skills were significantly predictory of academic achievement [10]. According to and cited in Ridgell [11], research in the past decade has also found several Big 
Five predictors of academic success: Agreeableness and Conscientiousness [12]; Conscientiousness [12-14], and Openness [15]. In addition, O' Conner \& Paunonen (2003) found a relationship across the Big Five assessments to academic achievement [16]. In context to the above researches it can be seen that these factors are closely related to academic achievement, so it has been thought these factors can play a role in case of test anxiety which is also related to academic achievement. So in this paper an attempt has been made to identify the personality and behavioural factors associated with test anxiety.

\subsection{Objectives:}

1. To investigate whether there is any relationship between aggression and test-anxiety among adolescents.

2. To investigate whether there is any relationship between emotional intelligence and test-anxiety among adolescents.

3. To investigate whether there is any relationship between the personality dimensions and test-anxiety among adolescents.

4. To investigate whether the above mentioned factors will be the predictors of Test anxiety

\subsection{Hypothesis:}

1. There is a significant correlation between reactive aggression and test-anxiety among adolescents.

2. There is a significant correlation between proactive aggression and test-anxiety among adolescents.

3. There is a significant correlation between emotional intelligence and test-anxiety among adolescents.

4. There is a significant correlation between extraversion and test-anxiety among adolescents.

5. There is a significant correlation between neuroticism and test-anxiety among adolescents.

6. There is a significant correlation between psychoticism and test-anxiety among adolescents.

7. Reactive aggression will be a significant predictor of test-anxiety.

8. Proactive aggression will be a significant predictor of test-anxiety.

9. Emotional Intelligence will be a significant predictor of test-anxiety.

10. Extraversion will be a significant predictor of test-anxiety.

11. Neuroticism will be a significant predictor of test-anxiety.

12. Psychoticism will be a significant predictor of test-anxiety.

\subsection{Participants}

\section{Method}

Data was collected from 143 adolescents from different Higher Secondary Schools in Kolkata, West Bengal. The sample consisted of class 11 and 12 students, from all the educational streams (arts, science and commerce) and both sexes were taken in the study. It was a cross-sectional correlational design and purposive sampling was followed.

\subsubsection{Inclusion Criteria:}

1. Age of the participants should range from 15-18 years.

2. Staying with family members at present.

3. Informed consent was taken.

\subsubsection{Exclusion Criteria:}

1. History of significant physical, psychological or neurological condition.

2. History of Mental Retardation, Epilepsy or Head Injury.

3. Single parent child.

\subsection{Tools}

2.2.1 Socio-Demographic Data Sheet: It is a semi structured Performa. It contained information about sociodemographic variables like name, age, education, class, number of siblings, stream in which he/she is studying, name of father and mother, address, telephone number and email address. Information was taken so as to ensure that the participant was living with his/her parents, with both parents living and the participant didn't have a history of any physical, psychological or neurological problems.

2.2.2 Reactive-Proactive Aggression Questionnaire [17]: The Reactive-Proactive Aggression Questionnaire consists of twenty-three items and consists of 3 point response pattern, where 0 means never, 1 means sometimes and 2 means often. The scale consist of two subscales reactive aggression and proactive aggression. The proactive aggression items are $(2,4,6,9,10,12,15,17,18,20,21,23)$ and reactive items are $(1,3,5,7$, $8,11,13,14,16,19,22)$ are summated to form proactive and reactive scales. Proactive and reactive scale scores are summated to obtain total aggression scores. All three scales have internal reliabilities in excess of 0.83 
2.2.3 Test attitude Inventory [18]: The Test Anxiety Inventory (TAI) is a self-report inventory designed to measure test anxiety (TA) as a situation-specific personality trait. The TAI is recommended for use in research and clinical settings. The Test Anxiety Inventory was designed to measure the worry and emotionality components of test anxiety. It has a 4-point Likert type scale in responding to the eight items used to assess each component [18] presented average Cronbach alpha reliability coefficients for five normative samples of .88 for the worry component and .90 for the emotionality component. Test-retest coefficients for a high school student sample varied from .81 (a 1-month delay) to .62 (a 6-month delay). Correlations with five other anxiety measures (ranging from .51 to.82) were cited as evidence of validity.

2.2.4 Self- Report Emotional Intelligence Scale [19]: The self-report questionnaire by Schutte et al (1998) comprises 33 self-referencing statements and requires subjects to rate the extent they agree or disagree with each statement on a 5 -point scale ( $1=$ strongly disagree; $5=$ strongly agree $)$.

2.2.5 The Junior Eyesenk Personality Questionnaire [20]: The JEPQ is a child version of the adult Eysenck Personality Questionnaire. It is comprised of 81 items standardized on a sample of 3,387 children (1,751 males and 1,636 females). Ages of the sampled participants ranged from 7 through 15 years. The questionnaire assesses the three personality traits (P, E, and $\mathrm{N})$ used in Eysenck's theory of personality and includes a Lie (L) scale score assessing a person's inclination to give socially expected responses. Test-retest reliability scores on the $\mathrm{P}, \mathrm{N}, \mathrm{E}$, and $\mathrm{L}$ scales gathered over a one month period ranged from $\mathrm{r}=.61$ to .79 for children age 12 through 14 years. Internal reliability is moderate to high, $\mathrm{I}=.61$ to .85 [19].

\subsection{Procedure}

Initially permission was obtained from principals and school authorities of four Higher Secondary Schools in Kolkata from where data was collected. There after informed consent was taken from student after considering the inclusion and exclusion criteria. The students were explained the purpose of the study. To ensure full cooperation it, was emphasized that anonymity would be ensured and they need not write names. They were also reassured that none of results would be disclosed with the school authorities. They were then asked individually to fill the Questionnaire booklet which contained Socio-Demographic Data Sheet followed by Reactive-Proactive Aggression Questionnaire, Test-Anxiety Scale, Emotional Intelligence Scale and Junior Eyesenk Personality Questionnaire. The scoring of the tools was done as per the test manuals. The results were tabulated. The data was analysed with SPSS program and Pearson's Product Moment correlation and Regression was done.

\section{Results}

Socio demographic details of the subjects in the study are shown in Table $1 \& 2$. Mean age of study sample was $(M=16.51$, S.D. $=0.922$. There are $65(45 \%)$ male and $78(55)$ female participated in the study and mean $(\mathrm{M}=1.55$, S.D. $=0.47)$.

The mean and S.D. of the variables are as follows, proactive aggression $(\mathrm{M}=3.86 ; \mathrm{SD}=3.54)$, reactive aggression $(\mathrm{M}=8.47 ; \mathrm{SD}=3.67)$, aggression $(\mathrm{M}=12.33 ; \mathrm{SD}=6.28)$, test anxiety $(\mathrm{M}=39.49 ; \mathrm{SD}=10.78)$, emotional intelligence $(M=121.50 ; S D=22.17)$, extraversion $(M=15.63 ; S D=3.91)$, neuroticism $(M=9.98$; $\mathrm{SD}=4.25)$, psychoticism $(\mathrm{M}=4.52 ; \mathrm{SD}=2.60)$ (Table 3$)$.

Pearson's product-moment correlation was computed to determine the linear relationships among test anxiety, aggression, emotional intelligence and personality dimensions. The correlations showed significance between test anxiety and reactive aggression $(r=.316, p<.02)$, test anxiety and aggression $(r=-.240, p<$ $.01)$, test anxiety and emotional intelligence $(r=-.176, p<.05)$, test anxiety and neuroticism $(r=-.409, p<$ $.01)$ and test anxiety and psychoticism $(r=.270, p<.01)$ (Table 4). These correlations indicated that as reactive aggression and aggression increases test anxiety thoughts increases. On the other hand we find that emotional intelligence bears a negative correlation with test anxiety. In case of the personality variables we found that neuroticism and psychoticism bear a positive correlation with test anxiety. Here hypothesis $1,3,5$ and 6 are accepted.

Table 5 shows the regression table of the variables with test-anxiety. Here we find that reactive aggression (beta $=.170 ; \mathrm{p}=.043$ ), emotional intelligence (beta $=-.164 ; \mathrm{p}=.033$ ) and neuroticism (beta $=.331 \mathrm{p}$ $=.000)$ have emerged as possible predictors of test-anxiety, together they explained $22 \%$ of the variance. So we can say that hypothesis 7,9 and 11 . 
Personality and behavioural factors associated with Test-anxiety among schools students in Kolkata.

Table 1: Distribution of Socio-Demographic characteristics of study sample

\begin{tabular}{|l|l|l|l|}
\hline \multirow{2}{*}{ Socio-Demographic Details } & Adolescents (N=143) \\
\cline { 2 - 4 } & Sex & Frequency & Percentage (\%) \\
\cline { 2 - 4 } & Female & 65 & 45 \\
\hline \multirow{2}{*}{ Class } & 11 class & 78 & 55 \\
\cline { 2 - 4 } & 12 class & 85 & 41 \\
\hline
\end{tabular}

Table 2: Mean and SD of Socio Demographic Variable

\begin{tabular}{|l|l|l|l|}
\hline $\begin{array}{l}\text { Socio-Demographic } \\
\text { Details }\end{array}$ & $\mathrm{N}$ & Mean & S.D. \\
\hline Age & 143 & 16.51 & .922 \\
\hline
\end{tabular}

Table 3: Mean and SD of the Variables

\begin{tabular}{|l|r|l|r|}
\hline Variables & $\mathrm{N}$ & & S.D. \\
\hline Proactive Aggression & 138 & 3.8623 & 3.54778 \\
\hline Reactive Aggression & 138 & 8.4710 & 3.67313 \\
\hline Aggression & 138 & 12.3333 & 6.28674 \\
\hline Test-Anxiety & 138 & 39.4928 & 10.78946 \\
\hline Emotional Intelligence & 138 & 121.5072 & 22.17556 \\
\hline Extraversion & 138 & 15.6377 & 3.91878 \\
\hline Neuroticism & 138 & 9.9855 & 4.25979 \\
\hline Psychoticism & 138 & 4.5217 & 2.60044 \\
\hline
\end{tabular}

Table 4: Correlation between Test-Anxiety and other variables among Adolescents

\begin{tabular}{|c|c|c|c|}
\hline Variables & Correlation & & \\
\hline \multirow[t]{3}{*}{ Proactive Aggression } & Product Moment Correlation & 1 & .098 \\
\hline & Sig. (2 tailed) & & \\
\hline & $\mathrm{N}$ & 143 & \\
\hline \multirow[t]{3}{*}{ Reactive Aggression } & Product Moment Correlation & 1 & $.316^{* *}$ \\
\hline & Sig. (2 tailed) & & \\
\hline & $\mathrm{N}$ & 143 & \\
\hline \multirow[t]{3}{*}{ Aggression } & Product Moment Correlation & 1 & $.240^{* * *}$ \\
\hline & Sig. (2 tailed) & & \\
\hline & $\mathrm{N}$ & 143 & \\
\hline \multirow[t]{3}{*}{ Emotional Intelligence } & Product Moment Correlation & 1 & $-.176^{*}$ \\
\hline & Sig. (2 tailed) & & \\
\hline & $\mathrm{N}$ & 143 & \\
\hline \multirow[t]{3}{*}{ Extraversion } & Product Moment Correlation & 1 & 088 \\
\hline & Sig. (2 tailed) & & \\
\hline & $\mathrm{N}$ & 143 & \\
\hline \multirow[t]{3}{*}{ Neuroticism } & Product Moment Correlation & 1 & $.409^{* *}$ \\
\hline & Sig. (2 tailed) & & \\
\hline & $\mathrm{N}$ & 143 & \\
\hline \multirow[t]{3}{*}{ Psychoticism } & Product Moment Correlation & 1 & $.270^{* * *}$ \\
\hline & Sig. (2 tailed) & & \\
\hline & $\mathrm{N}$ & 143 & \\
\hline
\end{tabular}

Table 5: The Results of a Multiple Regression Analysis for Reactive Aggression, Emotional Intelligence, Anger-Out, Anger-Expression, Trait Anger and Personality Dimensions Predicting Test-Anxiety

\begin{tabular}{|l|r|r|r|}
\hline Variable & Standardized Beta & $\mathrm{t}$ & $\mathrm{p}$ (two-tailed) \\
\hline Reactive Aggression & .170 & 2.042 & .043 \\
\hline Emotional Intelligence & -.164 & -2.159 & .033 \\
\hline Neuroticism & .331 & 4.149 & .000 \\
\hline
\end{tabular}

$\mathrm{R}$ square $=.250$

Adjusted R square $=.227$

www.iosrjournals.org 


\section{Discussion}

The present study explored the relationship between the personality and behavioural variables that included aggression and its dimensions, emotional intelligence and personality dimensions and test-anxiety among school students and to find out the possible predictors of test anxiety. From the correlation matrix we find that test-anxiety has a significant and positive correlation with reactive aggression, neuroticism and psychoticism and it has a significant negative correlation with emotional intelligence. Regressional analysis also reveals that reactive aggression, emotional intelligence and neuroticism have emerged as possible predictors of test-anxiety.

The correlation matrix shows that there is positive correlation of test-anxiety with reactive aggression, neuroticism and psychoticism. Reactive aggression is uniquely characterized by impulsivity, hostility, social anxiety, lack of close friends, unusual perceptual experiences, and ideas of reference. This relationship is very interesting in nature because we find that aggression that involves characteristics such as overt expression bears a positive correlation with test-anxiety. One reason for the link between aggression and anxiety may be the existence of social-cognitive biases that lead anxious and aggressive children to interpret benign or ambiguous social or evaluative situations as threatening. Past research has shown that overtly aggressive children exhibit such cognitive biases [21] and reactively aggressive youth exhibit them at a higher rate than proactive aggressive youth [22]. It has been already found that anxiety may also play a role in the manifestation of reactive aggression. Compared to proactive aggressive children, reactive aggressive children are more likely to have a history of abuse and anxiety disorder symptoms [7-8]. So it may be possible that test-anxiety is positively correlated and predicted by reactive aggression itself.

In case of emotional intelligence we find a negative correlation. Test anxiety is also negatively predicted by emotional intelligence. Emotional intelligence is the ability to monitor one's own and other's feelings and emotions to discriminate among them and to use this information to guide one's thinking and action [23]. So we find that people who are adept in monitoring one's own feeling and emotions and discriminate among them and use this information tactfully in practical purposes and generally have low test anxiety level. That is in case of threatening examination they are able to use their emotional resources to guide one's thinking and action and in this way they tend to perceive test situation as less threatening. Recent researches have depicted the role of emotional intelligence in academic success in education [9], stating that EI skills can significantly predict academic achievement [10].

Neuroticism is an enduring tendency to experience negative emotional states. Individuals who score high on neuroticism are more likely than the average to experience such feelings as anxiety, anger, envy,guilt, and depressed mood. [24]. It is probably for this reason that test anxiety is positively correlated and predicted by neuroticism. Also Speilberger (1979) found that students with high-test anxiety tend to blame themselves for their poor performance, while low test-anxious students did not. He also found that high test- anxious students apparently respond to examination stress with intense emotional reactions and negatively self-attributed thoughts that impair the performance, while those low in test anxiety react with increased motivation and concentration [25]. We know that negative emotional reactions and self blame or self-derogatory thoughts are associated with neuroticism. Further, Neuroticism is also associated with negative physical consequences such as racing heart, perspiration, gastric disturbances and muscle tension [26], all of which may negatively contribute to academic achievement (impairing study habits and attendance). Previous researches have provided us with findings showing the relationship between academic performance and Neuroticism which is usually understood in terms of anxiety, particularly under stressful conditions such as university examinations [2]. From a psychological point of view, it has been shown that Neuroticism is related to poor self-concept [27]. This may in turn develop anxiety about examinations or evaluative situations among students. This provides sufficient basis for our findings showing that test anxiety is positively correlated and predicted by neuroticism.

While this paper mainly focussed only on the personality and behavioural factors, it would be better if an in depth examination could be done on the cognitive factors and psychosocial factors (like parental expectations and social influence) underlying test anxiety or evaluative anxiety.

\section{Conclusion}

This study basically highlighted the personality and behavioural factors associated with the development of test anxiety. Emotional intelligence, reactive aggression and neuroticism have emerged as possible predictors of test anxiety. This study could be further improved by including variables such as underlying cognitive dimensions, coping strategies, social support systems, and study skills and habits underlying test anxiety and to find the factors that differentiate high and low test anxiety students who have similar academic performance. Parental factors also need close examination as it can work both as a facilitator and protector of test anxiety and possible interventions can be suggested on that basis. Finally school-based efforts should also be taken into consideration and efforts should be taken to reduce excessive academic stress. 


\section{References}

[1] A. Aboulghasemi, \& B. Nadjarrian, Test Anxiety: Causes of Assessment and treatment, Psychological Researches, 1999 , 82-95.

[2] R. Hembree, Correlates, causes, effects, and treatment of Test Anxiety. Review of Educational Research, 58, $1988,47-77$.

[3]. M. Zeidner, Test Anxiety: The state of the art. (Plenum Press, NY, 1998)

[4]. M.S. Humphreys, \& W. Revelle, Personality, motivation, and performance: a theory of the relationship between individual differences and information processing. Psychological Review, 91, 1984, 153-184.

[5]. C. D. Spielberger, \& P. R. Vagg, Test anxiety: A transactional process, in C. D. Spielberger \& P. Vagg (Eds.), Test anxiety: theory, assessment, and treatment Washington, (DC: Taylor \& Francis, 1995) 3-14.

[6]. P.L. Hewitt, \& G.L. Flett, \& N.S. Endler,. Perfectionism, coping, and clinical depression. Journal of Clinical Psychology and Psychotherapy, 2, 1995, 47-58.

[7]. K. A. Dodge, J. E. Lochman, J. D. Harnish, J. E. Bates, \& G. S. Pettit, Reactive and proactive aggression in school children and psychiatrically impaired chronically assaultive youth, Journal of Abnormal Psychology, 106, 1997, $37-51$.

[8]. F. Vitaro, M. Brendgen, R. E. Tremblay, Reactively and proactively aggressive children: Antecedent and subsequent characteristics. Journal of Child Psychology and Psychiatry, 43, 2002, 495-505.

[9] M. J. Elias, A. Harriett, and C. S. Hussey, EQ+IQ=best leadership practices for caring and successful schools (Thousand Oaks, Calif.; London: Sage Publications, 2003).

[10]. B. G. Stottlemyer, An examination of emotional intelligence: Its relationship to achievement and the implications for education. doctoral diss., College of Graduate Studies. Kingsville, Texas A\&M University, 2002.

[11]. S. Ridgell, \& J. W. Lounsbury, Predicting collegiate academic success: General intelligence, "Big Five" personality traits, and work drive. College Student Journal, 38(4) 2004, 607 - 618.

[12]. B. A. Fritzsche, S. A. McIntire, \& Y. A. Powell, Holland type as a moderator of personality-performance predictions. Journal of Vocational Behavior, 60, 2002, 422-36.

[13]. V. V. Busato, F. J. Prins, J. J. Elshout, \& C. Hamaker, Intellectual ability, learning style, achievement motivation and academic success of psychology students in higher education. Personality and Individual Differences, 29, 2000, 1057-1068.

[14]. D. Musgrave-Marquart, S. P. Bromley, \& M. B. Dalley, Personality, academic attrition, and substance abuse as predictors of academic achievement in college students. Journal of Social Behavior \& Personality, 12(2), 1997, 501-511.

[15]. Paunonen, S. V., \& Ashton, M. C. (2001b). Big Five predictors of academic achievement. Journal of Research in Personality, 35, 78-90.

[16]. M. C. O’Connor, \& S. V. Paunonen, Big Five personality predictors of post-secondary academic performance. Personality and Individual Differences 43, 2007, 971-990.

[17]. A. Raine, K. A. Dodge, R. Loeber, L. Gatzke-Kopp, D. Lynam, C. Reynolds, The Reactive-Proactive Aggression Questionnaire: Differential correlates of reactive and proactive aggression in adolescent boys. Aggressive Behavior, 32, $2006,159-171$.

[18]. C. D. Spielberger, H. P. Gonzalez, C. J. Taylor, B. Algaze, G. R. Ross, L. G. Westberry, Test Anxiety Inventory. Sample Set, Test, Scoring: Preliminary Professional Manual. California: Consulting Psychologists Press Inc 1980.

[19]. N.S. Schutte, J.M. Malouff, L.E. Hall, D.J. Haggerty, J.T. Cooper, C.J. Golden, Development and validation of a measure of emotional intelligence. Personality and Individual Differences, 25, 1998, 167-177.

[20]. H. J. Eysenck, \& S. B. Eysenck, Eysenck personality questionnaire. San Diego: Educational and Industrial Testing Service, 1975.

[21]. N. R. Crick, \& D. A. Nelson, Relational and physical victimization within friendships: Nobody told me there'd be friends like these. Journal of Abnormal Child Psychology, 30, 2002, 599-607.

[22]. J. A. Hubbard, K. A. Dodge, A. H. N. Cillessen, J. D. Coie, \& D. Schwartz, The dyadic nature of social information processing in boys' reactive and proactive aggression. Journal of Personality and Social Psychology, 80, 2001, 268-280.

[23]. P. Salovey, \& J.D. Mayer, Emotional intelligence. Imagination, Cognition, and Personality, 9, 1990, $185-211$.

[24]. G. Matthews, D. R. Davies, S. J. Westerman, \& R. B. Stammers, Human performance. Cognition, stress, and individual differences. (London: Psychology Press, 2000).

[25]. C. D. Spielberger, Understanding stress and anxiety. (New York: Harper, 1979).

[26]. G. Matthews, and I. J. Deary, Personality traits. (Cambridge, UK: Cambridge University Press, 1998).

[27]. A. Wells, \& G. Matthews, Attention and emotion: a clinical perspective (Hove: Lawrence Erlbaum Associates, 1994). 